\title{
Intensification of microbial exopolysaccharide ethapolan synthesis on the mixture of energy-excessive substrates
}

\author{
Andrii Voronenko, Tetyana Pirog
}

National University of Food Technologies, Kyiv, Ukraine

\section{Keywords:}

Acinetobacter

Mixed substrates

Biosynthesis

Exopolysaccharides

Ethapolan

\section{Article history:}

Received 29.04.2021

Received in revised

form 02.09.2021

Accepted 30.09.2021

\section{Corresponding}

author:

Andrii Voronenko

E-mail:

voronenkoandr@ gmail.com

DOI: $10.24263 / 2304-$ 974X-2021-10-3-15

\section{Abstract}

Introduction. The cultivation conditions of Acinetobacter sp. IMV B-7005, providing maximum synthesis of exopolysaccharide (EPS) ethapolan on the mixture of ethanol and sunflower oil were studied, as well as the possibility of replacing refined oil in the mixture with ethanol on a waste one was demonstrated.

Materials and methods. Strain IMV B-7005 was grown in liquid mineral media, containing the mixture of ethanol and sunflower oil of various quality, as well as appropriate monosubstrates. The optimal molar ratio of the concentrations of substrates in the mixture was calculated theoretically according to Babel's concept. The EPS concentration was determined gravimetrically after precipitation with isopropanol, the EPSsynthesizing ability - as the ratio of the EPS concentration to the concentration of biomass and expressed in $\mathrm{g}$ EPS/g biomass.

Results and discussion. The highest rates of ethapolan synthesis were observed with the molar ratio of concentrations of ethanol and refined sunflower oil in the mixture of 1:0.056, as close as possible to the theoretically calculated (1:0.076), and the use of inoculum grown on ethanol. Further increasing of the concentrations of ethanol and oil led to a decrease in $\mathrm{pH}$ of the culture fluid to a suboptimal level for the EPS synthesis (4.5-4.8). To ensure the synthesis of ethapolan on a medium with high concentrations of ethanol $(4 \%)$ and oil $(1.2 \%)$ ammonium nitrate was replaced with an equimolar amount of nitrogen $\mathrm{KNO}_{3}(0.8 \mathrm{~g} / \mathrm{l})$, which is transported into cells by the symport with proton; fractional introduction of substrates in five equal portions during cultivation was carried out and was increased the concentration of $\mathrm{Mg}^{2+}$ cations, which are one of the activators of acetyl-CoA synthetase in Acinetobacter sp. IMV B-7005 affecting the enzymatic activity of systems responsible for the catabolism of fatty acids. Under such cultivation conditions, regardless of the type of used sunflower oil (refined or mixed waste) in the mixture with ethanol, the concentration of ethapolan reached 13.5-16.0 g/l, and EPS-synthesizing ability - 3.1-3.7 g EPS/g of biomass, which were respectively $3.2-3.8$ and $1.6-1.9$ times higher than before optimization.

Conclusions. Based on determining the optimal molar ratio of monosubstrate concentrations in the mixture, modification of the medium composition (replacement of ammonium nitrate with potassium nitrate, increasing the content of magnesium cations, replacement of refined oil on a mixed waste one) and fractional addition of substrates the possibility of intensification of ethapolan synthesis on the mixture of energy-excessive substrates (ethanol and sunflower oil) was established. 


\section{Introduction}

Production of microbial exopolysaccharides (EPS) is growing every year worldwide (Rana et al., 2020). This is mainly due to the physicochemical and functional properties of these polymers (gelling and emulsifying abilities, ability to retain a large amount of water and alter rheological properties of water systems, anticancer, antioxidant, antimicrobial, antiviral, anti-inflammatory, and immunomodulatory activities, etc.), which make possible their use in various industries, from food to petroleum (Barcelos et al., 2020).

Nevertheless, the same commercially successful EPS (xanthan, dextran, gelan, alginate, levan, pullulan, welan, scleroglucan, emulsan, hyaluronic acid, etc.), some of which have been known since the first half of the twentieth century, continue to be used in most industries for decades (Donot et al., 2012).

At the same time, most of the new microbial polysaccharides continue to be only at the stage of fundamental research (Zayed et al., 2021). Nowadays, the presence of unique properties is not enough for the industrial implementation of these polymers (Fukuda et al., 2021; Rana et al., 2020). In addition, they must be cheap, which in the biotechnological production of microbial EPS is mainly determined by the final concentration of the target product, the cost, and efficiency of consumption of carbon and energy sources (Barcelos et al., 2020).

One approach to the intensification of microbial synthesis and increasing the efficiency of substrates transformation into biomass and secondary metabolites is the use of a mixture of growth substrates (Babel et al., 1985; Pidhorskyy et al., 2010). In our previous studies, this approach has been successfully used to increase the polysaccharide ethapolan synthesis (produced by Acinetobacter sp. IMV B-7005) (Pidhorskyy et al., 2010).

The mixture usually consists of a combination of two substrates, which depending on the amount of energy generated during their catabolism to the central carbon precursor phosphoglyceric acid (PGA), are divided into energy-excessive and energy-deficient (Babel et al., 1985; Pidhorskyy et al., 2010).

If the amounts of ATP and reducing equivalents produced in the transformation of the substrate to PGA are sufficient for the synthesis of cellular components, such substrate is energy-excessive (Babel et al., 1985; Pidhorskyy et al., 2010). The substrates which must be partially oxidized to $\mathrm{CO}_{2}$ in order to obtain the energy necessary for constructive metabolism are energy-deficient (Babel et al., 1985; Pidhorskyy et al., 2010).

It should be noted that according to the classical concept of the auxiliary substrate, the use of a mixture of two energy-excessive substrates is not possible (Babel et al., 1985). Meanwhile, it is known about the possibility of using mixed substrates for both energy needs and biomass synthesis (Pidhorskyy et al., 2010).

We suggested that it can be possible to intensify the synthesis of ethapolan by using a mixture of two energy-excessive substrates. Ethanol and sunflower oil were selected as substrates for the studies, because during the growth on them high rates of ethapolan synthesis by strain IMV B-7005 were observed (Pidhorskyy et al., 2010).

In connection with the above, the aim of this work was to establish the cultivation conditions of Acinetobacter sp. IMV B-7005 for the maximum indicators of the exopolysaccharide ethapolan synthesis on the mixture of ethanol and sunflower oil, as well as to study the possibility of replacing the refined oil in the mixture with a waste one. 


\section{— Biotechnology, Microbiology}

\section{Materials and methods}

\section{Materials}

The strain Acinetobacter sp. 12S, deposited in the Depository of Institute of Microbiology and Virology, National Academy of Sciences of Ukraine under the number IMV B-7005 was used for microbial polysaccharide ethapolan synthesis (Pidhorskyy et al., 2010).

The complex polysaccharide preparation ethapolan consists of one neutral and two acidic EPS, one of which is acylated (AP). The acylated and non-acylated (NAP) polysaccharides are identical in molar ratios of $D$-glucose, $D$-mannose, $D$-galactose, $L$ rhamnose, $D$-glucuronic acid and pyruvic acid (3:2:1:1:1:1) and the structure of repeated unit of the carbohydrate chain. The difference between those EPS is that the acylated polysaccharide contains fatty acids $\left(\mathrm{C}_{12}-\mathrm{C}_{18}\right)$ (Pidhorskyy et al., 2010).

\section{Medium composition and cultivation conditions}

The IMV B-7005 strain was grown in such liquid mineral medium $(\mathrm{g} / \mathrm{l})$ : medium 1 (basic): $\mathrm{KH}_{2} \mathrm{PO}_{4}-6.8 ; \mathrm{KOH}-0.9 ; \mathrm{NH}_{4} \mathrm{NO}_{3}-0.6 ; \mathrm{MgSO}_{4} \times 7 \mathrm{H}_{2} \mathrm{O}-0.4$ (1.6 мM); $\mathrm{CaCl}_{2} \times 2 \mathrm{H}_{2} \mathrm{O}-0.1 ; \mathrm{FeSO}_{4} \times 7 \mathrm{H}_{2} \mathrm{O}-0.001$ (Pidhorskyy et al., 2010); medium 2 is similar to medium 1, but $\mathrm{NH}_{4} \mathrm{NO}_{3}$ was replaced with $\mathrm{KNO}_{3}(1.5 \mathrm{~g} / 1)$; medium 3 is similar to medium 2, but the concentration of $\mathrm{MgSO}_{4} \times 7 \mathrm{H}_{2} \mathrm{O}$ was $1.25 \mathrm{~g} / 1(5.0 \mathrm{mM})$.

An additional $0.5 \%(\mathrm{v} / \mathrm{v})$ of yeast autolysate was added into the medium, as well as the multivitamin complex "Complevit" at a concentration of 0.00085 (w/w by pantothenate) (Pidhorskyy et al., 2010; Pirog et al., 2020).

The following types of substrates were used as a carbon and energy source: monosubstrates - ethanol 1.66\% (v/v), refined sunflower oil 1.0\% (v/v); mixed substrates the mixture of ethanol (1.0-4.0\%) and refined oil (0.2-1.2\%). In one variant refined oil was replaced with the mixed waste one (after frying meat, potatoes, onions, cheese from "RockerPub", Kyiv).

In some variants the initial concentration of ethanol in the medium was $0.66-2.0 \%$ and oil $0.2-0.6 \%$, respectively. During the cultivation process every $24 \mathrm{~h}$ these substrates were fractionally applied (fed-batch) in portions (total $1-4$ portions) of $0.66-2.0 \%$ (ethanol) and $0.2-0.6 \%$ (oil).

The culture in exponential growth phase, grown in a medium with ethanol $(0.5 \%)$, oil $(0.5 \%)$ or the mixture of ethanol $(0.25 \%)$ and refined oil $(0.25 \%)$ was used as inoculum. Concentration of inoculum was 10\% (Pidhorskyy et al., 2010; Pirog et al., 2020).

Cultivation of IMV B-7005 strain was carried out in the flasks $(750 \mathrm{ml})$ with $100 \mathrm{ml}$ of medium in shaker $(320 \mathrm{rpm})$ at $30{ }^{\circ} \mathrm{C}$ for 120 hours (Pidhorskyy et al., 2010; Pirog et al., 2020).

\section{Biomass and ethapolan estimation}

Biomass concentration was determined by optical density of cell suspension with subsequent recalculation to dry biomass in accordance with the calibration curve (Pidhorskyy et al., 2010).

The amount of EPS was determined gravimetrically (Pidhorskyy et al., 2010). For this purpose, 1.5-2 volumes of isopropanol were added to a certain volume of the culture fluid (usually 10-15 ml). The EPS precipitate was washed with pure isopropanol and dried at room temperature for 24 hours.

EPS-synthesizing ability was calculated as the ratio of the EPS concentration to the 
biomass and expressed in g EPS/g biomass (Pidhorskyy et al., 2010).

\section{Determination of the optimal molar ratio of substrates concentrations}

Determination of the optimal molar ratio of substrates concentrations (ethanol and refined sunflower oil) in the mixture was based on the corresponding theoretical calculations (Pirog et al., 2020). Taking into account that during the metabolism of each energy-excessive substrate to PGA a sufficient amount of ATP and reducing equivalents for the synthesis of cell components is produced, it is necessary to: 1) calculate the energy generation during the EPS synthesis on each substrate; 2) determine the energy distribution of each substrate that occurs after the biomass synthesis.

Determination of energy expenditures for the formation of ethapolan from ethanol was calculated on the basis of the activity of Krebs cycle enzymes, glyoxylate cycle and gluconeogenesis of the strain Acinetobacter sp. IMV B-7005, as well as on the calculations as described earlier (Pidhorskyy et al., 2010). Energy generation in the catabolism of linoleic and oleic acids was calculated as described earlier (Pirog et al., 2020).

Since the ethapolan contains residues of fatty acids in its composition, during calculations it was additionally assumed that part of fatty acids of the oil can be used without significant transformations for the esterification of the carbohydrate chain of the EPS. Thus, after the biomass synthesis from fatty acids of oil and ethanol is generated 25 and $75 \%$ of total amount of energy, respectively. Other assumptions were similar to those described in the paper (Pirog et al., 2020).

\section{Statistical data processing}

All experiments were conducted in three repetitions; the number of parallel definitions in the experiments was from three to five. Statistical processing of experimental data was carried out as described earlier (Pidhorskyy et al., 2010; Pirog et al., 2020). Differences in average indicators were considered reliable at the level of significance $\mathrm{p}<0.05$.

\section{Results and discussion}

\section{Theoretical calculation of the optimal molar ratio of ethanol and sunflower oil in the mixture}

From the schemes shown in Figures 1 and 2, it is possible to calculate the amount of energy generated during the synthesis of the repeating unit of EPS from ethanol and fatty acids (oleic and linoleic) that prevail in the composition of sunflower oil. The corresponding summary data are represented in Table 1 and 2. 


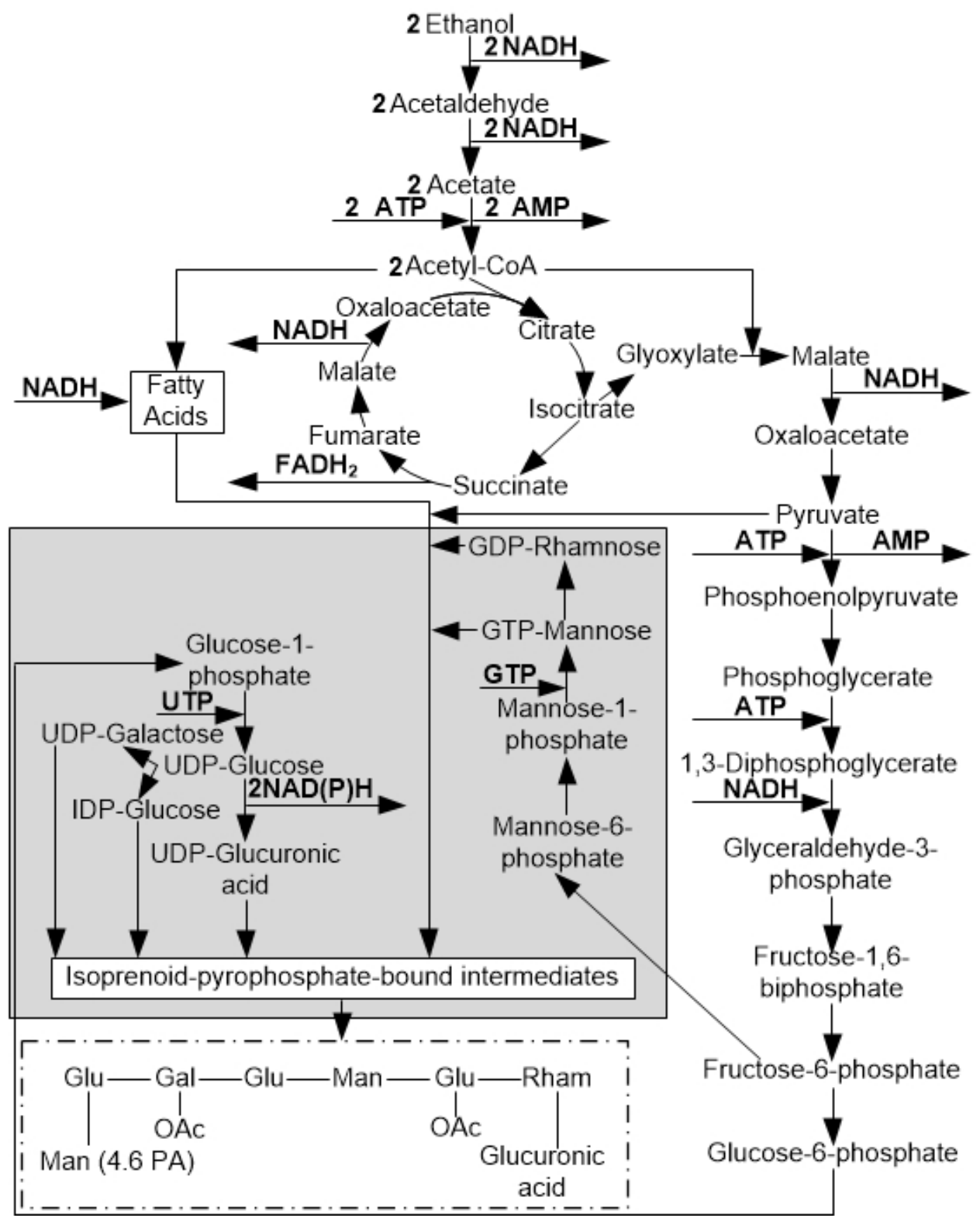

Figure 1. Synthesis scheme of repetitive units in the process of ethanol catabolism (literature data are grayed out) 


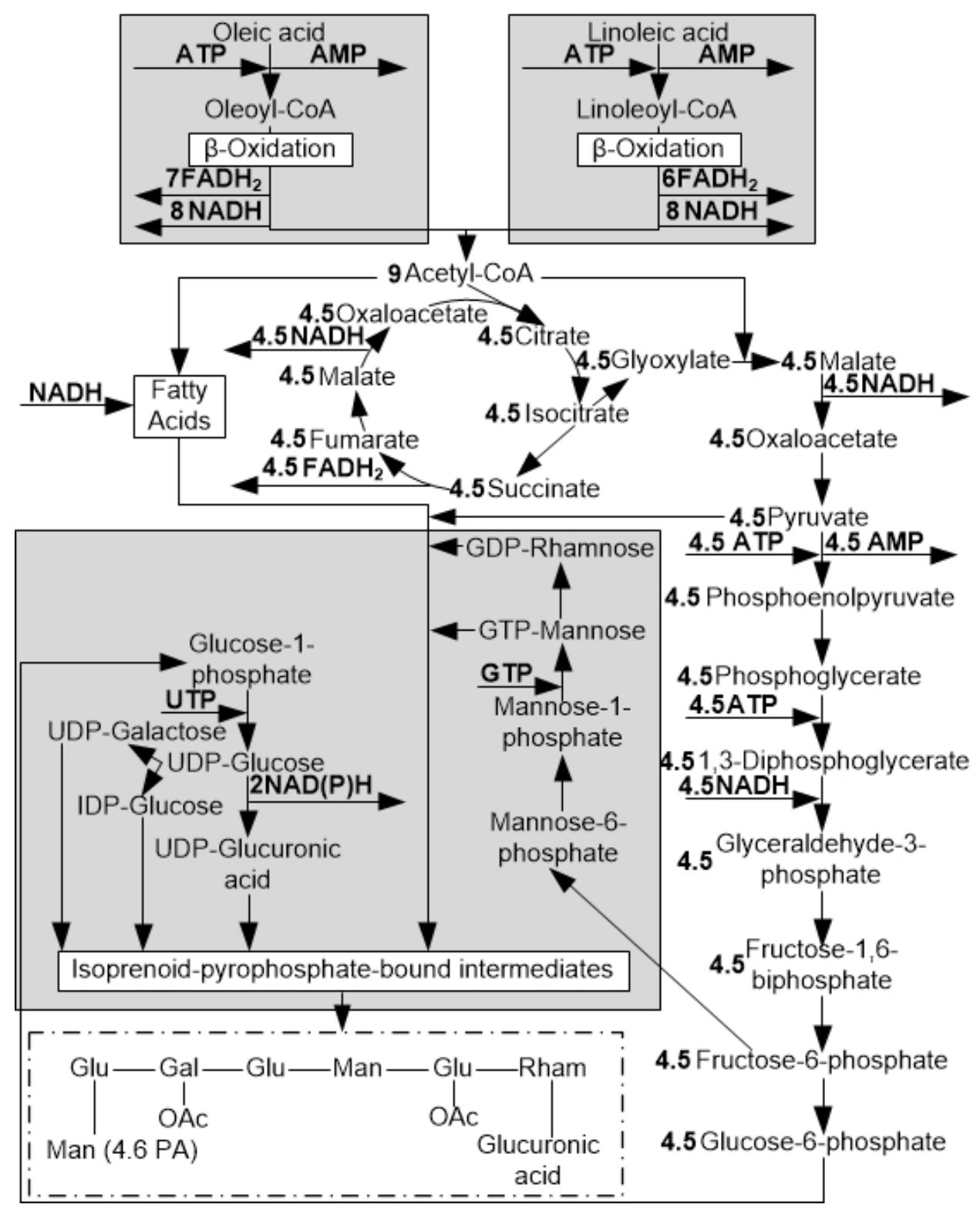

Figure 2. Synthesis scheme of repetitive units in the process of oleic and linoleic acids catabolism (literature data are grayed out) 
Table 1

Energy generation during synthesis of the EPS components from ethanol and sunflower oil

\begin{tabular}{|l|l|c|c|}
\hline $\begin{array}{c}\text { Substrate for } \\
\text { the EPS } \\
\text { biosynthesis }\end{array}$ & \multicolumn{1}{|c|}{ Stage } & $\begin{array}{c}\text { Consumption of } \\
\text { substrate for the } \\
\text { synthesis of the EPS } \\
\text { unit, mol }\end{array}$ & $\begin{array}{c}\text { Energy } \\
\text { generation, } \\
\text { mol ATP }\end{array}$ \\
\hline \multirow{4}{*}{ Ethanol } & $\begin{array}{l}\text { Synthesis of } \\
\text { monosaccharides }\end{array}$ & 16.00 & 51.00 \\
\cline { 2 - 4 } & Synthesis of fatty acids & 14.00 & 29.00 \\
\cline { 2 - 4 } & Synthesis of pyruvate & 2.00 & 11.00 \\
\hline \multirow{4}{*}{ Sunflower oil } & $\begin{array}{l}\text { Synthesis of } \\
\text { monosaccharides }\end{array}$ & 1.78 & 41.28 \\
\cline { 2 - 4 } & Synthesis of fatty acids & 2.00 & 12.00 \\
\cline { 2 - 4 } & Synthesis of pyruvate & 0.22 & 9.78 \\
\hline
\end{tabular}

Table 2

Energy expenditures of acylated and non-acylated polysaccharides synthesis from ethanol and sunflower oil

\begin{tabular}{|c|c|c|c|c|}
\hline \multirow{2}{*}{$\begin{array}{c}\text { Substrate for } \\
\text { the EPS } \\
\text { biosynthesis }\end{array}$} & \multirow[b]{2}{*}{ EPS } & \multirow{2}{*}{$\begin{array}{l}\text { Consumption of } \\
\text { substrate for the } \\
\text { synthesis of the } \\
\text { EPS unit, mol }\end{array}$} & \multicolumn{2}{|c|}{ Energy generation, mol ATP } \\
\hline & & & $\begin{array}{l}\text { for the EPS } \\
\text { unit synthesis }\end{array}$ & $\begin{array}{l}\text { per mol of } \\
\text { used acetate }\end{array}$ \\
\hline \multirow{3}{*}{ Ethanol } & AP & 32 & 91.00 & 2.84 \\
\hline & NAP & 18 & 62.00 & 3.40 \\
\hline & $\mathrm{AP}+\mathrm{NAP}$ & 50 & 152.00 & 3.04 \\
\hline \multirow{3}{*}{ Sunflower oil } & AP & 4 & 63.06 & 15.77 \\
\hline & NAP & 2 & 51.06 & 25.53 \\
\hline & $\mathrm{AP}+\mathrm{NAP}$ & 6 & 114.12 & 19.02 \\
\hline
\end{tabular}

Thus, the total energy expenditure for the synthesis of the repetitive unit of AP and NAP $(\mathrm{AP}+\mathrm{NAP})$ is: $3.04+19.02=22.06 \mathrm{~mol} \mathrm{ATP} / \mathrm{mol}$ of used substrate.

According to the calculations presented in (Pidhorskyy et al., 2010; Pirog et al., 2020), the energy generation during the conversion of ethanol and oil to PGA is 5.0 and $39.5 \mathrm{~mol}$ of $\mathrm{ATP} / \mathrm{mol}$ of the used substrate, respectively (equations 1 and 2).

$$
\begin{gathered}
\mathrm{C}_{2} \mathrm{H}_{5} \mathrm{OH} \rightarrow 0.5 \mathrm{PGA}+5 \mathrm{ATP} \\
0.5 \mathrm{C}_{17} \mathrm{H}_{31} \mathrm{COOH}+0.5 \mathrm{C}_{17} \mathrm{H}_{33} \mathrm{COOH} \rightarrow 4.5 \mathrm{PGA}+39.5 \mathrm{ATP} .
\end{gathered}
$$

Synthesis of biomass from PGA (using an ammonium nitrogen source) can be represented by the equation (Pidhorskyy et al., 2010):

$$
4 \mathrm{PGA}+\mathrm{NH}_{3}+29 \mathrm{ATP}+5.5 \mathrm{NAD}(\mathrm{P}) \mathrm{H} \rightarrow\left(\mathrm{C}_{4} \mathrm{H}_{8} \mathrm{O}_{2} \mathrm{~N}_{1}\right)_{3},
$$

where $\left(\mathrm{C}_{4} \mathrm{H}_{8} \mathrm{O}_{2} \mathrm{~N}_{1}\right)_{3}$ is the formula of one biomass mole. 
On the basis of the equation for biomass synthesis from PGA (Equation 3) and the equation of ethanol and oil catabolism to PGA (Equation 1 and 2), as well as the information shown in Table 2, it can be calculated that under cultivation on these substrates after synthesis of biomass and EPS remains 3.04 and $13.52 \mathrm{~mol} \mathrm{ATP} / \mathrm{mol}$ of used substrate, respectively, or $16.56 \mathrm{~mol}$ ATP in total.

Assuming that $75 \%$ and $25 \%$ of excess energy are generated from ethanol and oil, respectively, $4.09 \mathrm{~mol}$ of ethanol and $0.31 \mathrm{~mol}$ of oil are required to generate $16.56 \mathrm{~mol}$ of ATP, which corresponds to a molar ratio of 1:0.076.

For example, at an ethanol concentration of $1 \%(\mathrm{v} / \mathrm{v}, 10 \mathrm{ml} / 1$ or $8 \mathrm{~g} / 1,0.12 \mathrm{~mol})$, the oil concentration should be $0.013 \mathrm{~mol}$, or $3.66 \mathrm{~g} / \mathrm{l}$, or $3.98 \mathrm{ml} / \mathrm{l}$, or $0.4 \%(\mathrm{v} / \mathrm{v})$.

\section{Experimental verification of the molar ratio of concentrations of monosubstrates in the mixture}

It has been found that regardless of the method of inoculum preparation, the indicators of the ethapolan synthesis were 1.3-2.1 times higher than those obtained on the corresponding monosubstrates (Table 3). In further studies, the inoculum was grown on ethanol, because when used the concentration of the final product was maximum $(3.18 \mathrm{~g} / \mathrm{l})$.

Synthesis of ethapolan depending on the method of inoculum preparation

Table 3

\begin{tabular}{|c|c|c|c|}
\hline \multicolumn{2}{|c|}{$\begin{array}{c}\text { Concentration of substrates in the } \\
\text { medium for }\end{array}$} & EPS concentration, \\
g/l \\
biosynthesis, $\%$ & $\begin{array}{c}\text { inoculum } \\
\text { preparation, } \%\end{array}$ & $\begin{array}{c}\text { EPS-synthesizing } \\
\text { ability, } \\
\text { g EPS/g biomass }\end{array}$ \\
\hline \multirow{2}{*}{$\begin{array}{c}\text { Ethanol, 1.0, and } \\
\text { oil, 0.4* }\end{array}$} & Ethanol, 0.5 & $3.18 \pm 0.16$ & $1.85 \pm 0.09$ \\
\cline { 2 - 4 } & $\begin{array}{c}\text { Oil, 0.5 } \\
\text { Ethanol, 0.25, and } \\
\text { oil, 0.25 }\end{array}$ & $2.14 \pm 0.11$ & $1.39 \pm 0.07$ \\
\hline Ethanol, 1.66 & Ethanol, 0.5 & $1.49 \pm 0.07$ & $0.84 \pm 0.04$ \\
\hline Oil, 1.00 & Oil, 0.5 & $1.63 \pm 0.08$ & $0.93 \pm 0.05$ \\
\hline
\end{tabular}

Notes. 1. Cultivation was carried out in the medium 1. 2. ${ }^{*}-$ molar ratio of concentrations of ethanol and sunflower oil in the mixture was 1:0.076.

Since theoretical calculations, due to several assumptions, allow only to approximately determining the molar ratio of substrates in the mixture, the synthesis of polysaccharide at different molar ratios of ethanol and oil concentrations in the mixture was further investigated.

It was shown that the highest indicators of the ethapolan synthesis (EPS concentration $4.2 \mathrm{~g} / \mathrm{l}$, EPS-synthesizing ability $-2.0 \mathrm{~g}$ EPS/g biomass) were observed for the 1:0.056 molar ratio of monosubstrates in the mixture, maximally approximated to the theoretically calculated (1:0.076) (Table 4). In our opinion, this deviation from the theoretical ratio is due to the uneven involvement of each substrate in energetic and constructive metabolism. 
Table 4

Influence of molar ratio of ethanol and refined oil in the mixture on the ethapolan synthesis

\begin{tabular}{|c|c|c|c|c|}
\hline \multicolumn{2}{|c|}{$\begin{array}{c}\text { Concentration of } \\
\text { substrates in the mixture, } \\
\text { \% }\end{array}$} & $\begin{array}{c}\text { Molar ratio of } \\
\text { ethanol and oil }\end{array}$ & $\begin{array}{c}\text { EPS } \\
\text { concentration, } \\
\text { g/l }\end{array}$ & $\begin{array}{c}\text { EPS- } \\
\text { synthesizing } \\
\text { ability, } \\
\text { g EPS/g biomass }\end{array}$ \\
\hline ethanol & oil & & $2.10 \pm 0.11$ & $0.49 \pm 0.02$ \\
\hline 1.0 & 0.2 & $1: 0.036$ & $2.05 \pm 0.21$ & $2.00 \pm 0.10$ \\
\hline 1.0 & 0.3 & $1: 0.056$ & $4.23 \pm 0.10$ & $1.85 \pm 0.09$ \\
\hline 1.0 & 0.4 & $1: 0.076$ & $3.18 \pm 0.16$ & $1.20 \pm 0.06$ \\
\hline 1.0 & 0.5 & $1: 0.096$ & $2.94 \pm 0.15$ & $0.79 \pm 0.04$ \\
\hline 1.0 & 0.6 & $1: 0.116$ & $2.67 \pm 0.13$ & \\
\cline { 1 - 2 } & &
\end{tabular}

Notes. 1. Cultivation was carried out in the medium 1. 2. Inoculum was grown on ethanol.

\section{Intensification of ethapolan synthesis on the mixture of refined sunflower oil and ethanol}

One of the important indicators of the effectiveness of technologies for obtaining practically valuable microbial metabolites that directly affects the possibility of their industrial implementation is the concentration of the target product (Fukuda et al., 2021).

It should be noted that the indicators of EPS synthesis on mixed substrates depend not only on the optimal molar ratio of their concentration in the mixture, but also on the total concentration of monosubstrates in the mixture (Pidhorskyy et al., 2010).

Experiments have shown that increasing the concentrations of ethanol and oil in the mixture in two-folds to $2.0 \%$ and $0.6 \%$, respectively, was not only led to an increase in the amount of synthesized ethapolan by 1.2 times, but also was accompanied by a decrease in the $\mathrm{pH}$ of the culture fluid from 7.2 to 5.5 (optimum for the ethapolan synthesis 7.0-8.0). Further increase in the concentration of ethanol (3.0-4.0\%) and oil (0.9-1.2\%) in the cultivation media led to a drastic decrease in the indicators of EPS synthesis (EPS concentration 1.9-2.4 g/l, EPS-synthesizing ability - $1.0 \mathrm{~g} \mathrm{EPS} / \mathrm{g}$ biomass) and $\mathrm{pH}$ of the cultured fluid (4.5-4.8).

This decrease in $\mathrm{pH}$ can be due to several reasons, including the consumption of $\mathrm{NH}_{4} \mathrm{NO}_{3}$ through the antiport with proton and limitation of acetate metabolism due to low activity of acetyl-CoA synthetase, which catalyzes the assimilation of this substrate in the strain IMV B-7005. To solve this problem, the nitrogen source in the culture medium was replaced by an equimolar nitrogen concentration of $\mathrm{KNO}_{3}$, the assimilation of which is carried out by the symport with proton and is accompanied by an increase in $\mathrm{pH}$ of the cultural fluid, as well as fed-batch was applied.

It was found that when replacing the nitrogen source, regardless of the mode of fractional application of substrates, the $\mathrm{pH}$ of the culture fluid during cultivation was maintained at an acceptable level for the synthesis of EPS (Table 5). The highest rates of ethapolan synthesis (EPS concentration $13.5 \mathrm{~g} / \mathrm{l}$, EPS-synthesizing ability $3.5 \mathrm{~g}$ EPS/g biomass) were observed when reducing the initial concentration of monosubstrates in the mixture to $1 / 5$ of their total content, followed by their fractional application during the cultivation to the final concentration of ethanol $4.0 \%$ and oil $1.2 \%$. 
Table 5

Influence of nitrogen source replacement and fractional application of substrates on ethapolan biosynthesis on the mixture of ethanol and refined oil

\begin{tabular}{|c|c|c|c|c|c|}
\hline $\begin{array}{l}\text { Nitrogen } \\
\text { source }\end{array}$ & $\begin{array}{c}\text { Concen- } \\
\text { tration of } \\
\text { monosub- } \\
\text { strates in the } \\
\text { mixture, } \%\end{array}$ & $\begin{array}{c}\text { Fractional } \\
\text { substrate } \\
\text { addition mode* }\end{array}$ & pHend & $\begin{array}{c}\text { EPS } \\
\text { concen- } \\
\text { tration, g/l }\end{array}$ & $\begin{array}{c}\text { EPS- } \\
\text { synthesizing } \\
\text { ability, } \\
\text { g EPS/g } \\
\text { biomass }\end{array}$ \\
\hline \multirow{5}{*}{$\begin{array}{c}\mathrm{NH}_{4} \mathrm{NO}_{3} \\
\text { (medium 1) }\end{array}$} & \multirow{3}{*}{$\begin{array}{c}\text { Ethanol, 2.0, } \\
\text { and } \\
\text { oil, } 0.6\end{array}$} & $\begin{array}{l}\text { Without } \\
\text { fractional } \\
\text { application } \\
\text { (control) } \\
\end{array}$ & 5.5 & $5.01 \pm 0.25$ & $1.95 \pm 0.10$ \\
\hline & & $\begin{array}{c}\text { Two portions of } \\
1.0 \% \text { ethanol and } \\
0.3 \% \text { oil }\end{array}$ & 5.6 & $8.02 \pm 0.40$ & $1.81 \pm 0.09$ \\
\hline & & $\begin{array}{c}\text { Three portions of } \\
0.66 \% \text { ethanol } \\
\text { and } 0.2 \% \text { oil }\end{array}$ & 5.4 & $9.45 \pm 0.47$ & $2.65 \pm 0.13$ \\
\hline & \multirow{2}{*}{$\begin{array}{c}\text { Ethanol, 4.0, } \\
\text { and } \\
\text { oil, } 1.2\end{array}$} & $\begin{array}{c}\text { Two portions of } \\
2.0 \% \text { ethanol and } \\
0.6 \% \text { oil }\end{array}$ & 5.1 & $6.82 \pm 0.34$ & $1.40 \pm 0.07$ \\
\hline & & $\begin{array}{c}\text { Three portions of } \\
1.33 \% \text { ethanol } \\
\text { and } 0.4 \% \text { oil }\end{array}$ & 5.2 & $8.07 \pm 0.40$ & $1.25 \pm 0.06$ \\
\hline \multirow{7}{*}{$\begin{array}{c}\mathrm{KNO}_{3} \\
\text { (medium 2) }\end{array}$} & \multirow{3}{*}{$\begin{array}{c}\text { Ethanol, 2.0, } \\
\text { and } \\
\text { oil, } 0.6\end{array}$} & $\begin{array}{l}\text { Without } \\
\text { fractional } \\
\text { application } \\
\text { (control) }\end{array}$ & 7.0 & $5.16 \pm 0.26$ & $1.52 \pm 0.08$ \\
\hline & & $\begin{array}{c}\text { Two portions of } \\
1.0 \% \text { ethanol and } \\
0.3 \% \text { oil }\end{array}$ & 6.4 & $9.27 \pm 0.46$ & $2.10 \pm 0.11$ \\
\hline & & $\begin{array}{c}\text { Three portions of } \\
0.66 \% \text { ethanol } \\
\text { and } 0.2 \% \text { oil }\end{array}$ & 6.6 & $8.36 \pm 0.42$ & $2.17 \pm 0.11$ \\
\hline & \multirow{4}{*}{$\begin{array}{c}\text { Ethanol, 4.0, } \\
\text { and } \\
\text { oil, } 1.2\end{array}$} & $\begin{array}{c}\text { Two portions of } \\
2.0 \% \text { ethanol and } \\
0.6 \% \text { oil }\end{array}$ & 5.7 & $7.45 \pm 0.37$ & $1.18 \pm 0.06$ \\
\hline & & $\begin{array}{c}\text { Three portions of } \\
1.33 \% \text { ethanol } \\
\text { and } 0.4 \% \text { oil }\end{array}$ & 5.9 & $11.38 \pm 0.57$ & $1.59 \pm 0.08$ \\
\hline & & $\begin{array}{c}\text { Four portions of } \\
1.0 \% \text { ethanol and } \\
0.3 \% \text { oil }\end{array}$ & 5.9 & $11.88 \pm 0.59$ & $3.08 \pm 0.15$ \\
\hline & & $\begin{array}{c}\text { Five portions of } \\
0.8 \% \text { ethanol and } \\
0.24 \% \text { oil }\end{array}$ & 6.0 & $13.51 \pm 0.68$ & $3.65 \pm 0.18$ \\
\hline
\end{tabular}

\section{Notes:}

1. Inoculum was grown on ethanol.

2. * - during the cultivation process fractional addition of substrates was carried out every 24 hours 


\section{Replacement of the refined oil in the mixture with ethanol on a waste one}

It is known that substrate costs can be up to $50 \%$ of the final cost of the target product (Fukuda et al., 2021). To further reduce the cost of ethapolan, the refined oil in the mixture with ethanol was replaced on a mixed waste one, which is usually formed by mixing various fried oils before sending for utilization. It should be noted that these experiments were carried out with an additional increase in the cultivation medium of the concentration of $\mathrm{Mg}^{2+}$ cations, affecting the enzymatic activity of systems responsible for fatty acid catabolism and are one of the activators of acetyl-CoA synthetase in the producer of EPS.

It was established that with increasing content of $\mathrm{Mg}^{2+}$ up to $5 \mathrm{mM}$ in the medium with ethanol and waste oil, regardless of the mode of fractional addition of substrates (total 4 or 5 portions), an increase in the amount of synthesized polysaccharide to $15.5-16 \mathrm{~g} / \mathrm{l}$ was observed, which is higher than the synthesis indicators on the basic medium with ethanol and refined oil (10-13.5 g/l) (Table 6).

Table 6

Indicators of ethapolan synthesis on the mixture of ethanol (4.0\%) and sunflower oil (1.2\%) of different quality

\begin{tabular}{|c|c|c|c|c|c|}
\hline $\begin{array}{l}\text { Content of } \\
\mathrm{Mg}^{2+} \text { in the } \\
\text { medium, } \\
\text { MM }\end{array}$ & $\begin{array}{l}\text { Quality of } \\
\text { oil in the } \\
\text { mixture } \\
\text { with } \\
\text { ethanol }\end{array}$ & $\begin{array}{c}\text { Fractional } \\
\text { substrate } \\
\text { addition mode* }\end{array}$ & pHend & $\begin{array}{c}\text { EPS } \\
\text { concen- } \\
\text { tration, g/l }\end{array}$ & $\begin{array}{c}\text { EPS- } \\
\text { synthesizing } \\
\text { ability, } \\
\text { g EPS/g } \\
\text { biomass }\end{array}$ \\
\hline \multirow{4}{*}{$\begin{array}{c}1.6 \\
\text { (medium 2) }\end{array}$} & \multirow{2}{*}{ Refined oil } & $\begin{array}{c}\text { Four portions of } \\
1.0 \% \text { ethanol and } \\
0.3 \% \text { oil }\end{array}$ & 5.9 & $11.88 \pm 0.59$ & $3.08 \pm 0.15$ \\
\hline & & $\begin{array}{c}\text { Five portions of } \\
0.8 \% \text { ethanol and } \\
0.24 \% \text { oil }\end{array}$ & 6.1 & $13.51 \pm 0.68$ & $3.65 \pm 0.18$ \\
\hline & \multirow{2}{*}{$\begin{array}{c}\text { Mixed } \\
\text { waste oil }\end{array}$} & $\begin{array}{c}\text { Four portions of } \\
1.0 \% \text { ethanol and } \\
0.3 \% \text { oil }\end{array}$ & 6.2 & $12.02 \pm 0.60$ & $3.24 \pm 0.16$ \\
\hline & & $\begin{array}{c}\text { Five portions of } \\
0.8 \% \text { ethanol and } \\
0.24 \% \text { oil }\end{array}$ & 6.1 & $10.10 \pm 0.51$ & $2.73 \pm 0.14$ \\
\hline \multirow{4}{*}{$\begin{array}{c}5.0 \\
\text { (medium 3) }\end{array}$} & \multirow{2}{*}{ Refined oil } & $\begin{array}{c}\text { Four portions of } \\
1.0 \% \text { ethanol and } \\
0.3 \% \text { oil }\end{array}$ & 6.1 & $10.37 \pm 0.52$ & $2.58 \pm 0.13$ \\
\hline & & $\begin{array}{c}\text { Five portions of } \\
0.8 \% \text { ethanol and } \\
0.24 \% \text { oil }\end{array}$ & 6.2 & $9.86 \pm 0.49$ & $2.19 \pm 0.11$ \\
\hline & \multirow{2}{*}{$\begin{array}{c}\text { Mixed } \\
\text { waste oil }\end{array}$} & $\begin{array}{c}\text { Four portions of } \\
1.0 \% \text { ethanol and } \\
0.3 \% \text { oil }\end{array}$ & 6.0 & $15.63 \pm 0.78$ & $3.33 \pm 0.17$ \\
\hline & & $\begin{array}{c}\text { Five portions of } \\
0.8 \% \text { ethanol and } \\
0.24 \% \text { oil }\end{array}$ & 5.9 & $15.95 \pm 0.80$ & $3.11 \pm 0.16$ \\
\hline
\end{tabular}

Notes.

1. Inoculum was grown on ethanol.

2. * - during the cultivation process fractional addition of substrates was carried out every 24 hours. 
It turned out to be unexpected, but the additional introduction of $\mathrm{Mg}^{2+}$ into the medium with ethanol and refined oil led to a slight decrease in the synthesis of EPS. This may be due to the different effects of magnesium cations on the enzymatic systems responsible for the catabolism of fatty acids and other components of sunflower oil. For example, in Lactococcus lactis ssp. lactis concentration of $\mathrm{Mg}^{2+}$, which provides maximum enzymatic activity, differs for various enzymes of the $\beta$-oxidation system (Li et al., 2014).

According to literature date, the use of mixed substrates is primarily associated with the production of various microbial metabolites (enzymes, ethanol, methane, lipids, etc.) from lignocellulosic biomass (wood, straw, pulp, etc.) (Chukwuma et al., 2021). At the same time, information on the use of lignocellulose to obtain microbial EPS is limited (Liu et al., 2020; Wang et al., 2020; Wu et al., 2021).

Wu et al. (Wu et al., 2021) established the ability of Sphingomonas sanxanigenens NX02 to synthesize microbial EPS sanxan on a mixture of glucose and xylose. Regardless of the ratio of substrates in the mixture $(7: 3,5: 5,3: 7)$ their consumption rate, EPS concentration and biomass level in the first $24 \mathrm{~h}$ of cultivation were 1.1-2.3 times higher than those obtained on the corresponding monosubstrates. Meanwhile, at the end of cultivation the indicators were at the same level regardless of the type of used substrate (mono- or mixed). It should be noted that the replacement of refined carbohydrates with $4 \%$ (w/w by carbohydrates) of corn straw hydrolyzate (ratio of glucose and xylose $3.48: 1$ ) was accompanied by an additional increase in the amount of synthesized sanxan to $13.4 \mathrm{~g} / \mathrm{kg}$.

Other researchers (Liu et al., 2020) report the ability of Aureobasidium melanogenum TN2-1-2 on the medium containing $11 \%$ (w/w by carbohydrates) of wheat straw hydrolyzate (glucose to xylose ratio 78\%:22\%) to synthesize $55.1 \mathrm{~g} / 1$ of pullulan. During cultivation on corresponding monosubstrates (glucose and xylose) the EPS concentration was 58.3 and 50.2 $\mathrm{g} / \mathrm{l}$, respectively.

Note that the above producers due to the functioning of independent metabolic systems of glucose and xylose consumption grown in mixotrophic conditions.

Recently, new information about the EPS synthesis on mixture of waste substrates has appeared. Fathiyah et al. (Fathiyah et al., 2021) demonstrated the ability of Acetobacter xylinum to accumulate $4.5 \mathrm{~g} / \mathrm{l}$ of bacterial cellulose during growth on a mixture of oil palm frond juice and coconut water (optimal ratio 60:40). Under cultivation in a medium containing $8 \%$ (w/w by carbohydrates) of mixed fruit waste the strain Bacillus sp. SRA4 synthesized $25.1 \mathrm{~g} / \mathrm{l}$ EPS for $72 \mathrm{~h}$ (Vaishnav et al., 2020).

In the work (Gao et al., 2020) it was shown that additional application of $5.09 \%$ (w/w by carbohydrates) of cane molasses powder during solid-state cultivation of Kosakonia cowanii TL-1 strain on the medium, which contains a mixture of cane bagasse and broadbean seed capsule (optimal 2:1 ratio), was accompanied by an increase in the EPS yield in 7.16 times (up to $0.42 \mathrm{~g}$ of EPS/g of substrate).

One of the features of the microbial polysaccharide ethapolan, which distinguishes it from other known EPS, is the ability to use various oil-containing (refined and waste sunflower, olive oil, etc.) and $\mathrm{C}_{2}-\mathrm{C}_{6}$-substrates (carbohydrates, ethanol, acetate, organic acids, etc.), as well as their mixtures for its production (Pidhorskyy et al., 2010; Pirog et al., 2020).

It should be noted that nowadays information about the use of oil-containing substrates for microbial EPS is very limited, and in available data the concentration of the target product does not exceed a few grams per liter (Pirog et al., 2021; Pirog et al., 2016).

At the same time, this work demonstrated the possibility of obtaining $16 \mathrm{~g} / \mathrm{l} \mathrm{EPS} \mathrm{under}$ cultivation of strain IMV B-7005 on the mixture of ethanol and mixed waste oil. 


\section{Conclusion}

Thus, during the studies the possibility of microbial EPS ethapolan synthesis on a mixture of energy-excessive substrates (ethanol and sunflower oil) was established. To intensify the EPS synthesis, a comprehensive approach was used, which included:

1. Calculation and experimental confirmation of the optimal molar ratio of ethanol and refined sunflower oil concentration in the mixture (1:0.056);

2. Stabilization of $\mathrm{pH}$ of the medium at an acceptable level for the EPS synthesis while using high concentrations of ethanol and refined oil in the mixture (4\% and $1.2 \%$, respectively) by replacing the nitrogen source $\left(\mathrm{NH}_{4} \mathrm{NO}_{3}\right.$ with $\left.\mathrm{KNO}_{3}\right)$, establishing the optimal mode of fractional addition of substrates ( 5 equal portions during cultivation) and increasing the concentration of $\mathrm{Mg}^{2+}$ cations to $5.0 \mathrm{mM}$ (acetyl-CoA-synthetase activator);

3. Replacement of refined oil in the mixture with ethanol on a mixed one.

\section{References}

Babel W., Müller R.H. (1985), Mixed substrates utilization in microorganisms: biochemical aspects and energetics, Journal of General Microbiology, 131(1), pp. 39-45.

Barcelos M.C.S., Vespermann K.A.C., Pelissari F.M., Molina G. (2020), Current status of biotechnological production and applications of microbial exopolysaccharides, Critical Reviews in Food Science and Nutrition, 60(9), pp. 1475-1495.

Chukwuma O.B., Rafatullah M., Tajarudin H.A., Ismail N. (2021), A review on bacterial contribution to lignocellulose breakdown into useful bio-products, International Journal of Environmental Research and Public Health, 18(6001), pp. 1-27.

Donot F., Fontana A., Baccou J.C., Schorr-Galindo S. (2012), Microbial exopolysaccharides: Main examples of synthesis, excretion, genetics and extraction, Carbohydrate Polymers, 87(2), pp. 951-962.

Fathiyah S.M.S., Shahril M., Junaidi Z. (2021), Oil palm frond juice and coconut water as alternative fermentation substrate for bacterial cellulose production, IOP Conf. Series: Materials Science and Engineering, 1092(1), pp. 1-7.

Fukuda K., Kono H. (2021), Cost-benefit analysis and industrial potential of exopolysaccharides. In: Nadda A.K., K.V.S., Sharma S. eds., Microbial exopolysaccharides as novel and significant biomaterials, Springer, Cham, pp. 303339.

Gao H., Lu C., Wang H., Wang L., Yang Y., Jiang T., Li S., Xu D., Wu L. (2020), Production exopolysaccharide from Kosakonia cowanii LT-1 through solid-state fermentation and its application as a plant growth promoter, International Journal of Biological Macromolecules, 150, pp. 955-964.

Li L., Ma Y. (2014), Effects of metal ions on growth, $\beta$-oxidation system, and thioesterase activity of Lactococcus lactis, Journal of Dairy Science, 97(10), pp. 5975-5982.

Liu G., Zhao X., Chen C., Chi Z., Zhang Y., Cui Q., Chi Z., Liu Y.J. (2020), Robust production of pigment-free pullulan from lignocellulosic hydrolysate by a new fungus co-utilizing glucose and xylose, Carbohydrate Polymers, 241(116400), pp. 1-10.

Pidhorskyy V., Iutinska G., Pirog T. (2010), Intensification of microbial synthesis technologies, Naukova Dumka, Kyiv (in Ukrainian).

Pirog T., Yarosh M., Voronenko A. (2021), Synthesis of microbial exopolysaccharides on non-traditional substrates, Scientific Works of NUFT, 27(1), pp. $42-52$ (in Ukrainian).

Pirog T.P., Ivakhniuk M.O., Voronenko A.A. (2016), Exopolysaccharides synthesis on 
industrial waste, Biotechnologia Acta, 9(2), pp. 7-18.

Pirog T.P., Voronenko A.A., Yarosh M.B. (2020), Production of exopolysaccharide ethapolan under Acinetobacter sp. IMV B-7005 cultivation on the mixture of acetate and sunflower oil, Biotechnologia Acta, 13(4), pp. 71-80.

Rana S., Upadhyay L.S.B. (2020), Microbial exopolysaccharides: Synthesis pathways, types and their commercial applications, International Journal of Biological Macromolecules, 157, pp. 577-583.

Vaishnav A., Upadhayay K., Tipre D., Dave S. (2020), Utilization of mixed fruit waste for exopolysaccharide production by Bacillus species SRA4: medium formulation and its optimization, 3 Biotech, 10(12), pp. 1-9.

Wang J., Salem D.R., Sani R.K. (2020), Synthesis of biopolymers from a Geobacillus sp. WSUCF1 using unprocessed corn stover, ACS Sustainable Chemistry \& Engineering, 8(25), pp. 9483-9496.

Wu M., Zhao X., Shen Y., Shi Z., Li G., Ma T. (2021), Efficient simultaneous utilization of glucose and xylose from corn straw by Sphingomonas sanxanigenens NX02 to produce microbial exopolysaccharide, Bioresource Technology, 319, pp. 1-9.

Zayed A., Mansour M.K., Sedeek M.S., Habib M.H., Ulber R., Farag M.A. (2021), Rediscovering bacterial exopolysaccharides of terrestrial and marine origins: novel insights on their distribution, biosynthesis, biotechnological production, and future perspectives, Critical Reviews in Biotechnology, Advance online publication, pp. 1-21. 